\title{
Confusing, Dated and Ineffective? Current Sex Work Laws in England and Wales and Proposals for Reform
}

\author{
Jade Potot-Warren, Year 4 M Law Northumbria School of Law
}

Sex work is defined as 'a person who on at least one occasion and whether or not compelled to do so, offers or provides sexual services to another person in return for payment or a promise of payment to A or a third person' ${ }^{1}$. Sex work law is often controversial, and must balance the interests of the workers, the clients and the public. Examination of the relevant law relating to sex work, and the history and policy considerations that influenced it are crucial to understanding the principles that underpin the current law, as well as its application and flaws. There are a variety of critiques of England and Wales' current approach to sex work and the reforms put in place thus far, including criticism suggesting that the current law is in places confusing, dated and ineffective. I will suggest proposals for reform, aimed at clarifying and modernising UK sex work legislation. These proposals for reform will explore and compare existing alternative models that could potentially be adopted. The issues raised by legal transplants (i.e. 'the moving of a rule or a system of law from one country to another or from one people to another' ${ }^{2}$ in order for it to function as it did in the host jurisdiction ${ }^{3}$ ) are also a necessary consideration in the development of reform proposals.

Prostitution is a nuanced market with no single monolithic approach, and which is difficult to quantify and examine as sex workers are largely a hidden population (currently estimated at approximately $72,800^{4}$ in England and Wales). Firstly, there is no agreed definition for sex work/workers amongst researchers. Consequently, findings differ greatly ${ }^{5}$ depending on whether the chosen definition includes male, female, transsexual, street, online, or occasional

\footnotetext{
${ }^{1}$ Sexual Offences Act 2003, s.51(2)

2 Alan Watson, Legal Transplants: An approach to comparative law' (University of Georgia Press,1993) 21.

${ }^{3}$ Rosaline B Cowan, 'The effects of transplanting legislation from one jurisdiction to another' (2013), Vol 39, Issue 3, Commonwealth Law Bulletin

${ }^{4}$ Toynbee Hall, 'Statistics on prostitution in London and the UK', (Toynbee Hall June 2009)

5 ibid
} 
work. In addition, how sex workers identify themselves (or do not identify themselves as the case may be) may cause some difficulties. Many sex workers may not in fact consider themselves sex workers, particularly where the sex work is only occasional or is escort work ${ }^{6}$. The representation of the sex work markets is also problematic. The street market - which accounts for only around $28 \%$ of the sex work market ${ }^{7}$ - is often overrepresented, particularly because street sex workers are the most visible and easily accessible. The street market also attracts media attention, which sensationalises the sex work industry and almost exclusively focuses on female sex workers ${ }^{8}$, overlooking other markets and making male and transsexual workers an even less visible population. In contrast, the 'off-street' market of sex work is much less visible, although it is growing ${ }^{9}$. Generally, the street market has a lower age of entry ${ }^{10}$, because unlike in brothels, escort services and so on, there are no controls or limits imposed by managers or websites. Many brothels also will not employ sex workers with drug problems, and so these sex workers turn to the street market to finance their addiction.

Historically, the law relating to sex work was primarily nuisance centred. Emphasis was on the public/private divide as criminal law was 'not charged to enter into matters of private moral conduct' ${ }^{11}$ but rather it's role was 'to preserve public order and decency, to protect the citizen from what is offensive and injurious ${ }^{12}$. Consequently, the law principally aimed to criminalise women on the streets and eliminate 'unsightly' brothels. Reform has been attempted through the Sexual Offences Act (SOA) (2003) and the Policing \& Crime Act (PCA) (2009).

The SOA demonstrates a shift in legislative focus, changing from targeting nuisance to targeting management, exploitation and pimps to reflect the growing concerns surrounding trafficking and exploitation. A principle concern with this act, is the definition of prostitute this act sets out, namely the inclusion of 'whether or not compelled to do $\mathrm{so}^{13}$, There is no

\footnotetext{
${ }^{6}$ Erin Fitzgerald et al., 'Meaningful Work: Transgender Experiences in the Sex Trade', (National Centre Transgender Equality, 2015)

${ }^{7}$ Hillary Kinnel, Violence and Sex Work in Britain, (Willan Publishing 2008)

${ }^{8}$ Beran K, 'Revisiting the Prostitution Debate: Uniting Liberal and Radical Feminism in Pursuit of Policy Reform' (2012) 30(1) LAW \& INEQ $<$ https://scholarship.law.umn.edu/cgi/viewcontent.cgi?article=1140\&context=lawineq $>$ accessed 27/03/2018

${ }_{9}^{9}$ Teela Sanders, Jane Scoular, Rosie Campbell, Jane Pitcher, Jane Pitcher, Stewart Cunningham, Internet Sex Work: Beyond the Gaze, (Palgrave, 2018)

${ }^{10}$ Marianne Hester, Nicole Westmarland, 'Tackling Street Prostitution: A Holistic Approach', (Home Office Research, Development and Statistics Directorate, 2004)

${ }^{11}$ Home Office, Scottish Home Department Report of the Committee on Homosexuality Offences and Prostitution (Cmnd 247, 1957)

12 ibid

${ }^{13}$ Sexual Offences Act 2003, s.51(2)
} 
differentiation between prostitution where the sex worker has chosen to do sex work and 'forced' prostitution, i.e. exploitation or trafficking. Therefore, the act is ineffective in targeting management and prostitution in general and dangerously, not only criminalises but also fails to protect victims of forced prostitution.

The Coordinated Prostitution Strategy of 2006 brought some focus back to targeting nuisance, though it did include aims to reduce all form of commercial sexual exploitation. Its key objectives were to challenge the idea that street prostitution was inevitable; to overall reduce street prostitution; and to ameliorate the safety and quality of life of communities affected by prostitution, including those directly involved in street sex markets ${ }^{14}$. Following the recommendations of the 2006 strategy, the PCA (2009) was introduced for further reform and reflected the shift towards targeting the client, based on the idea that sex work could be reduced by targeting demand. One of the most significant and arguably, dangerous effects of the Act was the introduction of the strict liability offence (one can be liable for the actus reus alone 'there is no mens rea element to prove') of 'Causing, inciting or controlling prostitution for gain $^{15}$ '. In practice, the only way a sex worker may legally sell sex is if they are 'working alone, in a property they own, without explicitly advertising or financially supporting another person' ${ }^{16}$. The sheer breadth of what could constitute 'control' leaves sex workers at a potentially even higher risk of harm. For example, landlords or people employed as maid or security for sex workers may deemed to be 'in control' (and therefore liable) because they stand to gain from the prostitution as it provides their employment. This hugely restricts the degree of control a sex worker has in how and where they conduct their business and leaves them extremely vulnerable.

Section 14 of the 2009 Act which governs the paying for sexual services of a prostitute subject to force is also problematic - more specifically, subsection 2, which states that, in determining whether the client has committed an offence, it is irrelevant 'whether A [the client] is, or ought to be, aware that $\mathrm{C}$ [a third person] has engaged in exploitative conduct ${ }^{17}$. It is only right that paying for the sexual service of a prostitute subjected to force be an offence - as this relates to abuse and even trafficking, not sex work. However, several issues arise from the irrelevance of

\footnotetext{
${ }^{14}$ Home Office, A Coordinated Prostitution Strategy, (London 2006)

${ }^{15}$ Sexual Offences Act 2003, s.52-53

16 Teela Sanders, Sex Work: A Risky Business (Willan: Devon, 2005) 94.

${ }^{17}$ Policing and Crime Act 2009, s.14(2)(b)
} 
the client's knowledge. Although the strict liability element of this offence was intended to increase the likelihood of conviction, in practice it means that a client can be liable whether there was any way of knowing the sex worker was subjected to force ${ }^{18}$ or not. Therefore, where clients might otherwise report suspected force, abuse or exploitation, they are less likely to do so in case they are found to have committed an offence, thus making those subjected to exploitation even less visible and therefore less likely to receive the help and protection they need $^{19}$. Furthermore, this section is rarely used ${ }^{20}$ as coercion or 'force' is difficult to establish which makes it ineffective in preventing exploitation and deterring the purchase of sexual services, instead leaving sex workers open to harm.

The significant amount of legislation and frequent shifts in its underpinning ideology over a span of only 6 years demonstrates how controversial and even subjective sex work and the perceived issues can be. Furthermore, it is another example of the difficulties of legislating for a hidden population - it can be unclear who or what should be targeted and the scale of the issue at hand, consequently decisions are based largely on estimations which in turn may produce ineffective and unclear laws. Approaches to sex work are broadly divided into professionalisation or criminalisation. UK legislation focuses on sex work and the issues it raises as criminal matters ${ }^{21}$, which inevitably precludes sex workers from being acknowledged as potential victims, professionals in their own right or anything other than criminals. Consequently, sex workers are left open to harm with no recourse for protection against harm or exploitation. June 2016 saw somewhat of a deviation from the criminalisation approach taken thus far, when the Home Affairs Select Committee's inquiry ${ }^{22}$ concluded that the laws relating to brothel keeping and soliciting should be decriminalised to promote the safety of sex workers rather than criminalising them ${ }^{23}$. These findings were prompted by an increased awareness of the risks the current sex work legislation posed to both sex workers and the wider

\footnotetext{
${ }^{18}$ Sarah Kingston and Terry Thomas, 'The Police, Sex Work, and Section14 of the Policing and Crime Act 2009', (2014) 53 Howard Journal of Criminal Justice 255260

${ }^{19}$ Laura Graham, 'Governing sex work through crime: creating the context for violence and exploitation' (2017) 81(3) The Journal of Criminal Law 201

${ }^{20}$ Sarah Kingston and Terry Thomas, 'The Police, Sex Work, and Section14 of the Policing and Crime Act 2009', 53 Howard Journal of Criminal Justice 255 at 262 (2014).

${ }^{21}$ Laura Graham, 'Governing sex work through crime: creating the context for violence and exploitation' (2017) 81(3) The Journal of Criminal Law 201

${ }^{22}$ Home Office, Paying the Price: A Consultation Paper on Prostitution (Home Office: London, 2004); Home Office, A Coordinated Prostitution Strategy (Home Office: London, 2006); Home Office, Tackling the Demand for Prostitution: A Review (Home Office: London, 2008); APPG, All Party Parliamentary Group on Prostitution and the Global Sex Trade, Shifting the Burden: Inquiry to Assess the Operation of the Current Legal Settlement on Prostitution in England and Wales (APPG: London, 2014).

${ }^{23}$ House of Commons Home Affairs Committee, Prostitution, HC 26 (2016), para. 102.
} 
community, and consequently should be the catalyst for a change in England and Wales' legislative approach and for reform of what is currently, at least in places, outdated and ineffective law. When considering reform options, it is important to have regard to the influences and ideology which shape the reform and particularly relevant here are feminist approaches.

Diversity in feminist thought stems from a complex cultural, class, race, national, sexual and other differences ${ }^{24}$. Two of the main schools of feminist thought are Radical and Liberal feminism. A radical feminist perspective draws no distinction between voluntary sex work and forced prostitution, arguing that prostitution is inherently abusive and "a form of male sexual violence against women" 25 . Rebuking arguments that prostitution is a choice, radical feminists instead argue that prostitution can never be freely chosen because it is rooted in the sale (and therefore objectification) of women's body ${ }^{26}$. In contrast to this is the liberal feminism approach which argues that "humans are rational, autonomous individuals" 27 and as such, a sex worker is an independent contractor who is able to start and stop transactions ${ }^{28}$. Liberal feminism is centred on using the law to bring about change, calling for decriminalisation and/or regulation of the industry on the basis that "autonomy over one's body includes the right to offer a sexual service in exchange for money, goods, or other services" 29 .

The 'prostitution as abuse' approach of radical feminists is, in my opinion, an overly moralistic one, which by holding sex to be something which can affect one's worth and esteem suggests an inherent connection between sex/sexuality and selfhood. This connection appears exaggerated, when in reality it is much subtler and for some, perhaps even non-existent - many sex workers simply view their profession as work and do not consider it demeaning ${ }^{30}$. Moreover, I would argue that a distinction between sex work/prostitution and forced prostitution could and should be drawn. Arguably, there is no such thing as 'forced prostitution', this is in fact exploitation, perhaps even trafficking, and should therefore be dealt

\footnotetext{
${ }^{24}$ Judith Lorber, The Variety of Feminisms and their Contribution to Gender Equality, (Oldenburg 1997)

${ }^{25}$ Sheila Jeffreys, The idea of prostitution, (Spinifex Press 1997) p. 5

${ }^{26}$ Catharine MacKinnon, Toward a Feminist Theory of the State, (Harvard University Press 1989)

${ }^{27}$ Sally J Scholtz, Feminism (Oxford: Oneworld Publications 2010), 15.

${ }^{28}$ Carole Pateman, The Sexual Contract, (Stanford University Press, 1995), p. 202.

${ }^{29}$ Kimberly Lux (2009), 'Work, Violence, or Both? Framing the Sex Trade and Setting an Agenda for Justice', (University of Chicago Advocates Forum 2009) p.1-14

${ }^{30}$ Anti-Slavery International, October 1993, p. 4
} 
with differently in the law to reflect this, offering protection and decriminalisation for the victim, and harsher punishments for the client/exploiter to reflect the harm caused.

I would also argue that radical feminism adopts too theoretical an approach as it focuses on symbolism and 'value' but offers few effective practical solutions. Sex work/prostitution, will most likely happen regardless of the legislative stance. Therefore, it would seem to be in the interest of all sex workers to acknowledge this and regulate sex work accordingly in the law to ensure safety of those involved. Whilst I acknowledge there may be an ideological battle to be fought regarding permanent demand for sexual services and objectification or domination of women, this is of little help to sex workers currently suffering or at risk because of the current legislation. Through the media's (and to an extent, the law's) construction of prostitutes as social outcasts, the public subconsciously views prostitutes as legitimate targets of violence, in turn reinforcing social hierarchies ${ }^{31}$. There is a need for laws which enable sex workers to work safely and which provide support and legal protection for victims. The approach taken by New Zealand exemplifies such legislation, and has proven immensely successful in achieving these aims.

The New Zealand model is constructed around the decriminalisation of sex work between adults, with certain restraints, such as prohibiting child sex work ${ }^{32}$ and imposing regulations on advertising ${ }^{33}$ and brothels ${ }^{34}$, in place. The 2003 Prostitution Reform Act (PRA) has provided a vital framework for sex workers, enabling them to report violence and harassment, resolve employment disputes and seek health care. Although the stigma cannot be 'legislated away', the law reflects the shift in attitudes and has served as a catalyst to reduce the stigma. Studies have also confirmed the success of this model in improving relations with the police and encouraging access to health care: of 772 sex workers interviewed around the country, $73 \%$ said they chose to work for the money, $87 \%$ visited the doctor regularly (though only about half revealed their occupation) and $60 \%$ felt that the police cared for their safety. Interestingly, there has not been an increase in the number of sex workers, thus refuting the argument that a more permissive approach would in fact encourage prostitution. However, the current New

\footnotetext{
${ }^{31}$ Ann Russo, 'Lesbians, Prostitutes, and Murder: Media Constructs Violence Constructs Power' in Martha A. Fineman and Martha T. McCluskey (eds), Feminism, Media \& The Law (OUP, 1997)

32 Prostitution Reform Act (2003), s.20-23

${ }^{33}$ Prostitution Reform Act (2003), s.11

${ }^{34}$ Prostitution Reform Act (2003), s.8-9
} 
Zealand model bars migrant workers from the industry ${ }^{35}$, leaving them potentially vulnerable to marginalisation and harm. There are also reports of instances where brothels are not consistently closely or regularly monitored ${ }^{36}$. This may be because the industry has developed since the original reformation in 2003, and it may be timely to update or reinforce certain provisions. The adoption of the New Zealand model would allow England and Wales to officially recognise sex workers as legitimate workers, granting them protection through better relations with the police and access to employment law. Importantly, this model would appear to be appropriate to both the social and legal culture of England and Wales, and legal transplants are likely to be successfully implemented where the legal institutions are functionally comparable ${ }^{37}$.

In contrast, the Nordic abolitionist model is another popular recommendation for reform in England and Wales, as current legislation already seems to be 'mimicking the abolitionist tone of Sweden, short of criminalising all purchases of sexual services and decriminalising the activities of those who sell sex ${ }^{38}$. This model is founded upon the premise that all sex work is inherently abusive, the aim being to reduce the sex industry and send a symbolic message that women are not for sale, which was implemented by the criminalisation of the purchaser and decriminalisation of the prostitutes. Also introduced, were social programmes to educate and deter women from entering prostitution and to encourage and support women in exiting prostitution $^{39}$.

In an effort intended to protect sex workers - or specifically, women in the sex industry - the move to decriminalise sex workers is a positive one. There are however, significant problems with this model. Firstly, the social welfare provision, although good in theory, is extremely narrow, targeted primarily at women and women who want to exit, ${ }^{40}$ claiming that the majority

\footnotetext{
${ }^{35}$ Prostitution Reform Act (2003), s.19

${ }^{36}$ Julie Bindel, The Pimping of Prostitution: Abolishing the Sex Work Myth, (Palgrave, 2017)

${ }^{37}$ Mary Gardiner, "Come Spring: The Australian Fair Pay Commission as Legal Transplants" (2007) 20 AJLL 159 at $160-1$.

${ }^{38}$ Anna Carline, Jane Scoular, Eilis Ward (ed), Gillian Wylie (ed), 'Almost abolitionism: the peculiarities of prostitution policy in England and Wales', (Oxon 2017) Feminism, Prostitution and the State Abingdon: the Politics of Neo-abolitionism., pp. 103-120

${ }^{39}$ Max Waltman, 'Prohibiting Sex Purchasing and Ending Trafficking: The Swedish Prostitution Law', (2011) 33(1) MJIL < https://repository.law.umich.edu/mjil/vol33/iss1/507> accessed 12/04/2017

${ }^{40}$ Coalition Against Trafficking in Women Australia (2017), 'Demand Change: Understanding the Nordic approach to prostitution', p.12
} 
of sex workers "just want out" 41 - there is consequently little to no support for those wishing to remain sex workers, and male and transsexual workers are ignored. This school of thought also fails to consider why sex workers may want to exit. For some, it may be true that this is not work that they would freely choose to do were it not for financial obligations or socioeconomic constraints. However, some workers may wish to exit not because of the work they do, but because of the conditions they are forced to work under - this would be particularly relevant in England and Wales where they are subjected to laws such as s.14 PCA. Under the abolitionist model, the sex workers who do not want to exit or are unable to, are not only unprotected but are also demonised. In practice, although sex work appears to have decreased in the on-street market, this is in fact not so much a decrease as it is a displacement ${ }^{42}$. The law in fact exacerbates the problem it seeks to address, as sex workers are increasingly marginalised and forced underground, where they are even less visible and more at risk of harm ${ }^{43}$.

Legal transplants can be hugely beneficial in so far as they "promote desirable social or legal changes which have been observed to arise from the implementation of such a law in other countries" 44 . However, legal transplants may also be problematic and may not translate. The most obvious potential issue is that of cultural differences. Laws and legal systems are inextricably linked to their host country, as its culture shapes not only the laws themselves but also the reasoning underpinning them and the attitudes towards their implementation. As a result, laws are often designed to tackle specific problems ${ }^{45}$ (sometimes in a specific way) which may not reflect the problems that England and Wales wishes to address or how it wishes to do so.

One viable option for reform in England and Wales would be to implement only certain aspects of the New Zealand model, or combine them with elements from other models. For example, the New Zealand model could be implemented combined with social welfare programmes similar to those set out in the Nordic model, but extended to include male and transsexual sex workers. If implemented in England and Wales, such educational programmes could raise

\footnotetext{
${ }^{41}$ Nordic Model Now (1 October 2017), 'Lies, Damn Lies and Ignoring Statistics: How the Decriminalisation of Prostitution is No Answer', <https://nordicmodelnow.org/2017/10/01/lies-damn-lies-and-ignoring-statisticshow-the-decriminalisation-of-prostitution-is-no-answer/> accessed 25/03/2018

${ }^{42}$ Commons Select Committee, Prostitution: The Sex Buyer Law, (HC 2016)

43 ibid

${ }^{44}$ Otto Kahn-Freund, in "On Uses and Misuses of Comparative Law" (1974) 37 Mod L Rev 1

${ }^{45}$ International Academy of Comparative Law, J. C. Gibson, Jorge A. Sánchez Cordero (ed.), 'Legal Culture and Legal Transplants', Volume 1 -Special Issue 1, Article 2, (Washington, D.C. 2010)
} 
awareness among sex workers regarding their rights, the support services available to them, and ways to work safely and in good health - unlike the Nordic model aimed at discouraging entering sex work.

Alternatively, England and Wales might simply reform some of the laws currently in force in lieu of transplanting a specific model. For example, redefining 'control' in the context of s.5252 of the SOA in order to allow sex workers to work in premises they rent or employ security staff without the risk that they could be liable would grant sex workers greater flexibility and safety in their work. This would also contemporise the law and arguably, make it more effective - particularly if in addition, 'prostitute' were redefined to mean 'voluntary prostitution', with separate definitions and provisions made for 'forced prostitution' (i.e. exploitation). For example, there should be stricter penalties for those involved in exploitation, whilst clients of 'voluntary prostitution' should arguably be decriminalised subject to the normal sexual offences and workers' rights laws.

Similarly, s.14(2) PCA calls for reform. This provision would have a clearer application apply and would be more effective in targeting exploitation if it were not a strict liability offence for the client. It might even be better governed in a separate section dealing specifically with exploitation and trafficking so as to more effectively target the exploiters and encourage reports of suspected exploitation.

In conclusion, sex workers are a significant (if somewhat hidden) population, currently subjected to criminalisation, marginalisation and numerous health risks - all of which they must face alone, as they are prevented from legally seeking help from peers, employing security and risk criminal consequences should they reach out to law enforcement. Certain elements of the current law (the PCA and SOA in particular), leave the sex worker very vulnerable, and clients at risk of being criminalised. Prostitution will most likely always be a part of society, and in any event, it is part of society now and so must be properly legislated. If the aim is to help and protect sex workers then repressive and ineffective legislation is certainly not the answer. Currently, the "exaggeration of the number of sex workers is being used to enforce more punitive measures, and reinforce a stereotype of sex workers as exclusively female and 
vulnerable ${ }^{46}$. Importantly, but often overlooked, is the fact that the law has the ability to play a significant part in guiding and shaping public opinion and morality. As such, the law should take care to not penalise or further stigmatise a section of the population that is already at high risk of harm.

Though legal transplants can be problematic, it seems that the New Zealand model would best address the socio-legal issue of sex work in England and Wales, specifically targeting the issues and gaps in current domestic legislation. It would mean a more definitive shift towards a decriminalisation and professionalisation model that is vital for the protection of sex workers and the reduction of exploitation. Moreover, the World Health Organisation suggests that decriminalising sex work could mean a reduction of $46 \%{ }^{47}$ in new HIV infections in sex workers, and that eliminating sexual violence against sex workers could lead to a $20 \%$ reduction ${ }^{48}$. Arguably, as a commonwealth legal system, the New Zealand model is also the most appropriate culturally, as there is already a significant degree of historical and cultural cross-fertilisation between the UK and commonwealth countries. As laws and their interpretation are often intrinsic to cultural and temporal contexts, such common ground is crucial to the likely success of a legal transplant. Therefore, the New Zealand model is perhaps easier to transplant than other models and more reflective of the direction we, as a nation, want to progress $\mathrm{in}^{49}$. Amongst the various proposals for reforms, each with their own successes and failures, there is one clear commonality - the need for reform. Sex workers, like other "socially excluded/marginalized and oppressed communities have always had to struggle to be represented in cultural and political discourses" $" 50$, but they deserve - and urgently need - the protection and the legitimacy they have thus far been denied ${ }^{51}$.

\footnotetext{
${ }^{46}$ Hillary Kinnell, 'Sex workers in England and Wales: Europap-UK Briefing Paper for Department of Health, National Sexual Health Strategy' (1999)

47 World Health Organisation, 'HIV/AIDS: Sex Workers', (World Health Organisation, 2016) $<$ http://www.who.int/hiv/topics/sex_work/en/> accessed 17/04/18

48 ibid

${ }^{49}$ Home Office, Paying the Price: A Consultation Paper on Prostitution (Home Office: London, 2004)

${ }^{50}$ Linda Cusick, Hillary Kinnel, Belinda Brooks-Gordon, Rosie Campbell, Wild guesses and conflated meanings? Estimating the size of the sex worker population in Britain (2009) 703

${ }^{51}$ Jill Nagel ed., Whores and Other Feminists, (Routledge, 1997) p.93
} 